\title{
Cowper's syringocele: an analysis of 15 consecutive cases
}

\author{
P Campobasso, E Schieven, E C Fernandes
}

\begin{abstract}
Cystic dilatation of Cowper's gland ducts (Cowper's syringocele) is uncommon in children and is frequently asymptomatic, but it may cause urinary infection, haematuria, dysuria, and obstructive voiding symptoms. Fifteen consecutive children with syringocele aged 15 days to 15 years old are reported here. Only four patients with obstructive syringocele were successfully treated surgically; all the others were successfully treated conservatively. The true clinical significance of Cowper's syringocele lies in its potential to cause urethral obstruction. Careful clinical, radiological, endoscopic, and urodynamic evaluation is necessary in order to avoid unnecessary surgery.

(Arch Dis Child 1996;75:71-73)
\end{abstract}

Keywords: Cowper's gland, syringocele, obstruction of lower urinary tract.

Syringocele is a cystic dilatation of the distal portion of Cowper's gland ducts. ${ }^{1}$ It is uncommon in children, but when it does occur it presents as urinary infection, haematuria, postvoiding incontinence, with obstructive symptoms, or may be totally asymptomatic.

We report 15 cases of syringocele in children.

Subjects, methods, and results

In the past 17 years, 15 boys had Cowper's syringocele diagnosed in our surgical department. Symptoms, diagnosis, and associated malformations are summarised in table 1 . Three patients with obstruction were treated successfully by endoscopic unroofing by Bugbee electrode.

A newborn infant with severe obstructive syringocele, bilateral megaureter, and renal failure was treated by Blocksom vesicostomy with reduction of ureteral dilatations and improvement in renal function at 18 months' follow up (fig 1). In two patients no treatment was performed and the remaining patients received medical treatment and were asymptomatic after 12-24 months.

\section{Discussion}

The Cowper's glands are the paired bulbourethral glands lying dorsally to and either side of the membranous urethra. The main Cowper's glands lie on the urogenital diaphragm; a second pair of accessory Cowper's glands lies deeply within the spongy tissue of the bulbar urethra and helps to account for the various presentations of Cowper's glands lesions. The ducts of these glands may open separately into the proximal bulbar urethra or unite to form a single duct.

Congenital obstruction of the mouth of the ductal orifice occurs by proliferation of the ductal epithelium resulting in congenital retention cysts and prestenotic ductal dilatation. ${ }^{2}$ Acquired obstruction may be postinflammatory after infection or prolonged urethral catheter drainage. ${ }^{3}$

Cowper's syringocele is often detected incidentally in asymptomatic patients. ${ }^{134}$ In other patients symptoms are variable; recurrent urinary infections, haematuria, irritative and obstructive voiding symptoms, enuresis, and postvoiding incontinence (in adults) have all been described. ${ }^{13-5}$ A severe obstructive syringocele may cause intrauterine or perinatal death and in the newborn may have devastating effects on the upper urinary tract, similar to those of the posterior urethral valve, with vesicoureteric reflux, severe hydronephrosis, and renal failure. ${ }^{2} 6$

Diagnosis is best made by voiding cystourethrography. Uroflowmetry is helpful in suspected obstructive syringocele and in postoperative follow up (fig 2). Endoscopy is performed to confirm diagnosis and/or to marsupialise the obstructive syringocele. ${ }^{134}$

Dilatation of Cowper's gland ducts is classified by Maizels et al and divided into four groups: (1) simple syringocele-a minimally dilated duct which permits reflux from the urethra into the duct; (2) perforate syringocelewhen the dilated distal portion of the duct drains in the bulbar urethra via a wide patulous

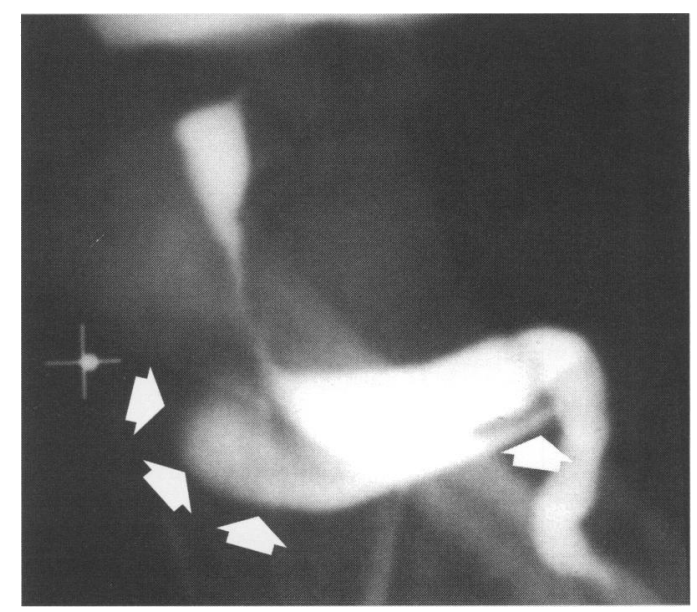

Figure 1 Newborn infant with suspected urethral valve (case 12). Cystourethrography shows obstructive syringocele (arrows) and trabeculated bladder. 
Table 1 Details of patients studied

\begin{tabular}{|c|c|c|c|c|c|c|}
\hline Patient No & Age (years) & Symptoms & Cystourethrography & Endoscopy & Associated malformations & Notes \\
\hline 1 & 4.8 & UTI, fever & NOS; bilateral VUR IV & Diagnostic & $\begin{array}{l}\text { VUR IV bilateral, } \\
\text { arthrogryposis, } \\
\text { micrognathia }\end{array}$ & Bilateral UR \\
\hline 2 & 14.0 & Right lumbar pain & NOS & - & $\begin{array}{l}\text { Dilation of upper right } \\
\text { collecting system, } \\
\text { apparently obstructed }\end{array}$ & $\begin{array}{l}\text { Radionuclide renal study } \\
\text { by }{ }^{99 m} \text { Tc DTPA } \\
\text { and diuretic test }\end{array}$ \\
\hline 3 & 6.2 & $\begin{array}{l}\text { Obstructive voiding } \\
\text { symptoms }\end{array}$ & os & Endoscopic unroofing & - & Uroflowmetry \\
\hline 4 & 9.0 & UTI & NOS & Diagnostic & - & Uroflowmetry \\
\hline 5 & 3.7 & $\begin{array}{l}\text { Obstructive voiding } \\
\text { symptoms }\end{array}$ & OS; left VUR III & Endoscopic unroofing & Right renal agenesis & Uroflowmetry \\
\hline 6 & 2.0 & $\begin{array}{l}\text { Post-traumatic } \\
\text { haematuria }\end{array}$ & NOS & - & - & Uroflowmetry \\
\hline 7 & 11.0 & Recurrent UTI & NOS & Diagnostic & - & $\begin{array}{l}\text { Previously endoscopic } \\
\text { unroofing in other } \\
\text { institution; uroflowmetry }\end{array}$ \\
\hline 8 & 15.0 & Recurrent UTI & NOS; left VUR III & Diagnostic & $\begin{array}{l}\text { Left VUR with severe } \\
\text { reflux nephropathy }\end{array}$ & Left nephrectomy \\
\hline 9 & 10.3 & Urinary incontinence & NOS & - & - & $\begin{array}{l}\text { Motor detrusor } \\
\text { instability (urodynamic } \\
\text { study) }\end{array}$ \\
\hline 10 & 9.0 & UTI & NOS & Diagnostic & - & - \\
\hline 11 & 12.6 & Urinary incontinence & NOS & - & $\begin{array}{l}\text { Neuropathic bladder } \\
\text { (spina bifida) }\end{array}$ & Urodynamic study \\
\hline 12 & 15 days & $\begin{array}{l}\text { Antenatal sonography: } \\
\text { bilateral dilated upper } \\
\text { collecting system and } \\
\text { large fluid filled fetal } \\
\text { bladder. Suspected } \\
\text { posterior urethral valve }\end{array}$ & OS; left VUR V & Diagnostic & $\begin{array}{l}\text { Bilateral megaureter; left } \\
\text { VUR V }\end{array}$ & Renal failure \\
\hline 13 & 2.0 & UTI, fever & NOS; bilateral VUR IV & Diagnostic & Bilateral VUR IV & Bilateral UR \\
\hline 14 & 2.0 & UTI, fever & NOS; left VUR III & Diagnostic & $\begin{array}{l}\text { Left VUR III with } \\
\text { renal scars }\end{array}$ & Left UR \\
\hline 15 & 3.0 & $\begin{array}{l}\text { Obstructive voiding } \\
\text { symptoms }\end{array}$ & os & Endoscopic unroofing & - & Uroflowmetry \\
\hline
\end{tabular}

OS = obstructive syringocele; UR = ureteral reimplantation; NOS = non-obstructive syringocele; UTI = urinary tract infection; VUR = vesicoureteric reflux.
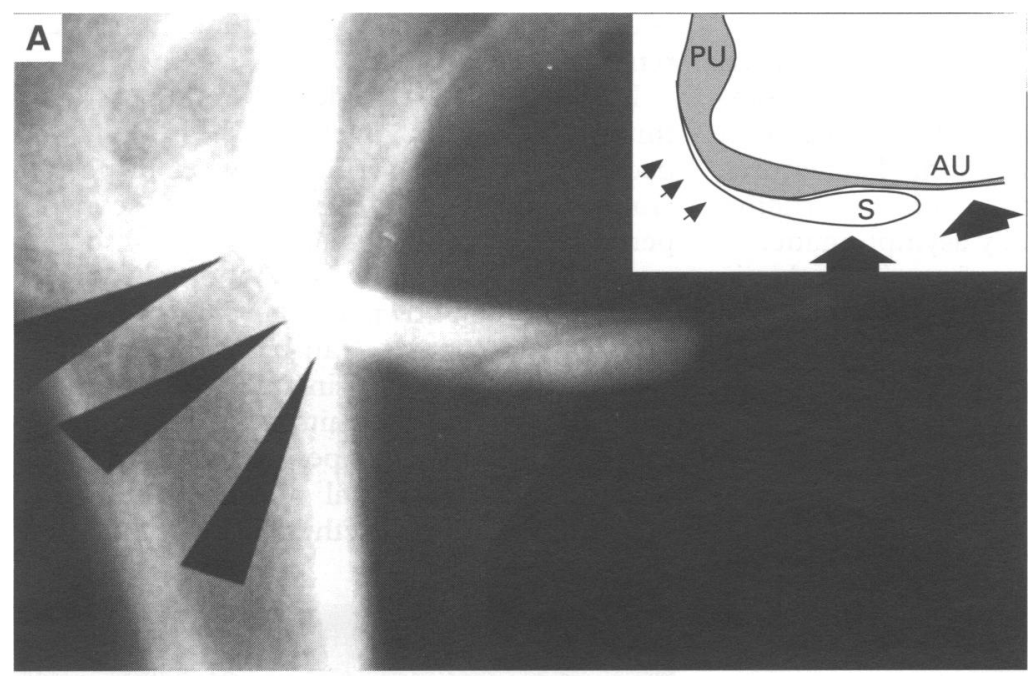

$\mathbf{B}$

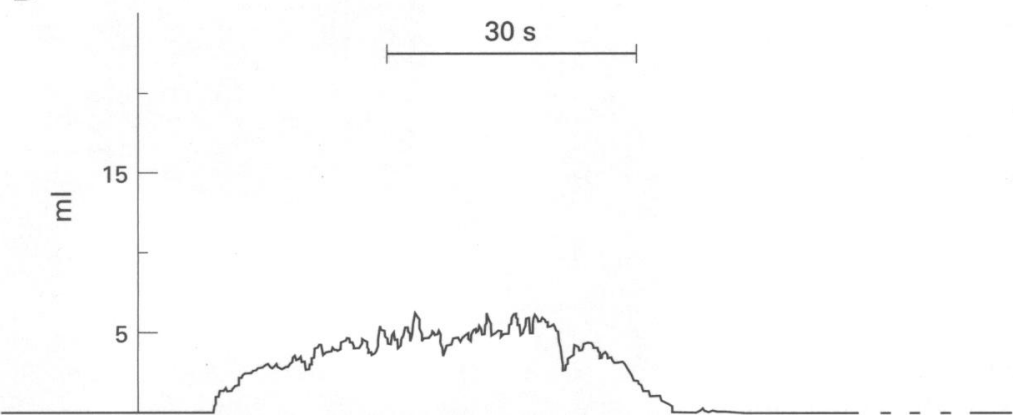

Figure 2 (A) Voiding cystourethrography in a patient with an obstructive syringocele (case 3). The posterior urethra (PU) is dilated, the syringocele is obstructive $(S)$, and the anterior urethra $(A U)$ seems to narrow because of the low flow rate. (B) Uroflowmetry of the same patient shows a flat trace, low maximum flow rate, and prolonged micturition time. orifice and appears as a diverticulum; (3) imperforate syringocele-a cystically dilated portion of the duct which compresses the urethra; and (4) ruptured syringocele-the fragile membrane remaining in the bulbar urethra after a rupture of the cystically dilated duct. ${ }^{1}$ This classification is based on the urethrographic and endoscopic appearances and is very important but not in itself an indication for treatment.

In our opinion it is more appropriate to classify syringocele into two groups: obstructive syringocele (groups 2 and 3 of the classification of Maizels et al) with significant straining to

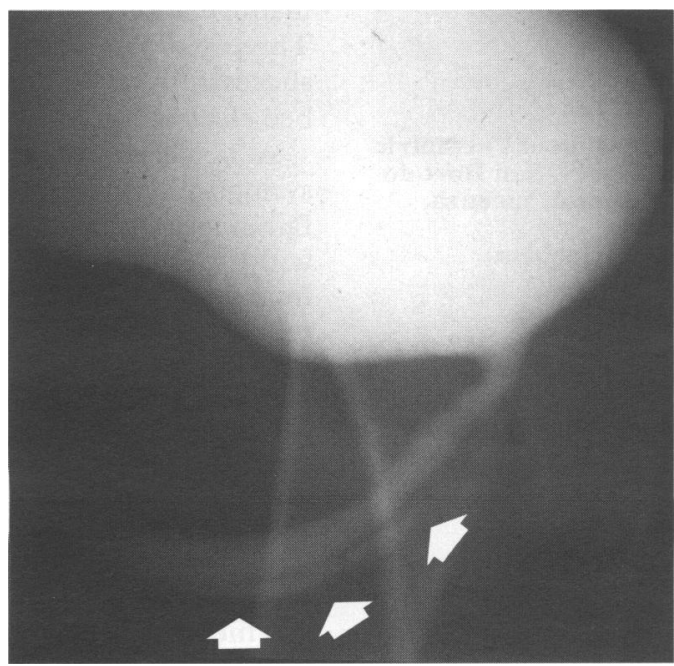

Figure 3 Voiding cystourethrography (case 8) showing a typical non-obstructive syringocele with urine reflux into Cowper's gland ducts (arrows). 
void and non-obstructive syringocele (groups 1 and 4 of their classification) (fig 3).

In the literature to date, all obstructive or symptomatic non-obstructive syringoceles were treated by surgery. ${ }^{13-5}$ In our experience only the obstructive group requires endoscopic or open surgery; non-obstructive symptomatic syringoceles are best treated medically.

The true clinical significance of Cowper's syringocele is the potential to cause urethral obstruction. Therefore, in paediatric practice, the syringocele must always be considered during evaluation of a boy with suspected obstruction of lower urinary tract. Careful clinical, radiological, endoscopic, and urodynamic evaluations are necessary in all cases of syringocele in order to avoid unnecessary surgery.

1 Maizels M, Stephens FS, King LR, Firlit CF. Cowper's syringocele: a classification of dilatation of Cowper's gland
duct based upon clinical characteristics of 8 boys. $f$ Urol 1983; 129: 111-4

2 Weinberger MA. Urethral cysts arising in Cowper's gland ducts. Etiology, pathogenesis and clinico-pathologic aspects. F Urol 1961; 85: 818-26.

3 Brock WA, Kaplan GW. Lesions of Cowper's glands in children. F Urol 1979; 122: 121- 3

4 Moskowitz PS, Newton NA, Lebovitz RL. Retention cysts of Cowper's duct. Radiology 1976; 120: 377-80.

5 Colodny AH, Lebowiz RL. Lesions of Cowper's ducts and glands in infants and children. Urology 1978; 11: 321-4.

6 Abrams HI, Joshi DP, Neier CR. Intrauterine urinary retention and electrolyte imbalance secondary to Cowper's gland cyst. $\mathcal{F}$ Urol 1966; 95: 565-9. 